\title{
Knowledge, attitude \& practices regarding Ethics \& Law amongst medical and dental professionals in Rajasthan - A Questionnaire study
}

\author{
Dr. Anup. $\mathrm{N}^{1}$, Dr. Himanshu Kumawat ${ }^{2}$, Dr. Gautam Biswas ${ }^{3}$, Dr. Sonia \\ Pareek $^{4}$, Dr. Swasti Tambi ${ }^{5}$ \\ 1) Professor and head. Department of Public health dentistry.Jaipur Dental College. \\ ${ }^{2)}$ PG Student. Department of Public health dentistry.Jaipur Dental College. \\ ${ }^{3)}$ Senior Lecturer. Department of Public health dentistry.Jaipur Dental College. \\ 4) Assistant Professor. Government Dental College.Jaipur. \\ ${ }^{5)}$ PG Student. Department of Public health dentistry.Jaipur Dental College.
}

\section{Introduction}

Ethics is a generic term referring to the moral code of conduct in a civil society and the rules, customs and beliefs of that society. It is generally agreed that 'morality' is all about what is right and wrong based on socially approved norms of human conduct. From childhood, we learn moral rules along with other social rules. Later in life, we are able to distinguish between general social rules held by all members of society, and specific social rules or ethical guidelines binding the members of special groups such as a health care profession. ${ }^{1}$ Healthcare ethics deals with how providers apply a moral code of conduct to patients in a healthcare setting, taking into account the patients' self respect, individuality, safety and welfare. ${ }^{2}$ Clinical ethics refers to the ethics of activity in the clinical setting, which if practiced, will lead to more ethical care.. For clinical personnel to practice clinical ethics, their clinical expertise and subject training need to be honed by appropriate clinical ethics training. ${ }^{3}$ Therefore they are expected to know ethical principles and apply them in their practice. ${ }^{4}$ There are reports of unethical behavioral patterns of medical students and medical and dental practitioners with patients as well as colleagues. Reports have stressed the need to incorporate ethical and legal issues into their curricula. ${ }^{5}$ Further it has been observed that health training in India provides little guidance for these professionals to resolve the ethical dilemmas they encounter. With this background the present study is an attempt to elucidate the knowledge, attitude and practice regarding ethics and law amongst medical and dental professionals in Rajasthan.

Aim- To compare Knowledge, attitude \& practice regarding Ethics \& Law among medical and dental professionals of Jaipur city.

\section{Objectives-}

- To assess knowledge, attitude \& practice regarding Ethics \& Law among medical\& dental professionals in Jaipur city.

- To compare knowledge, attitude \& practice regarding Ethics \& Law among medical \& dental professionals in Jaipur city.

- To compare knowledge, attitude \& practice regarding Ethics \& law among medical and dental professionals based on their qualifications.

- To assess the association between knowledge, attitude and practice and years of professional life among medical and dental professionals regarding ethics and law.

- To assess the association between Years of institutional attachment and knowledge, attitude and practice of medical and dental professionals regarding ethics and law.

- To assess the association between type of practice and knowledge, attitude and practice regarding ethics and law among medical and dental professionals.

\section{Materials And Method}

- Study Design:The present study was a descriptive, cross-sectional, questionnaire study conducted on medical and dental professionals of Jaipur city in September 2013.

- Study Participants:A sample of 230 participants, 115 in each group was taken.

- Sample Size: Sample size was deduced based on a previously conducted pilot study.

- Inclusion Criteria:All registered doctors who agreed to fill the questionnaire.

- Ethical Approval: Written permission was obtained from the respective principals of medical and dental colleges in Jaipur city. 
- Collection of data: A self-administered questionnaire was developed to determine the knowledge, attitude and practice which was framed by taking guidance from the previous literature regarding ethics and law in the developing world. The questionnaire consisted of 14 close-ended questions. The first section was designed to collect general information of the participants which included personal data and the socio-demographic profile. The next section of questionnaire had a variety of question formats which involved forced-choice selection response, yes/no response. The initial set of questions were designed to assess the knowledge of the respondents, next set to assess their attitude and last set was designed to assess their practice regarding ethics and law. The questionnaire was designed to take approximately 5 minutes to complete. A Pilot study was done with a select group of doctors (Medical \& Dental) to test its clarity and validity and were also asked to fill out the questionnaire and return with comments and criticism. Minor changes were made to final instrument.

Analysis

- In analyzing the results of the participants for the knowledge, attitude and practice questions, scores of 1 and 0 were assigned to true and false answers respectively. The numerical variables (e.g: years of professional life )were described numerically.

- For each parameter in the questionnaire, the percentages, means and standard deviations for each participant were calculated. The differences between subjects based on mean knowledge, attitude and practice score was assessed using t-test. The mean differences among participants based on their gender, years of professional life, years of any institutional attachment and qualification was analyzed using ANOVA test. The categorical data was analyzed using Chi-square test. The statistical significance level was considered as 0.05 . The data was analyzed using Microsoft office excel 2007 and SPSS version 18.0 software.

\section{Results}

Table 1. Age Distribution of Respondents

\begin{tabular}{|c|c|c|c|c|c|}
\hline Age(Yrs) & Dental & $\%$ & Medical & $\%$ & Grand Total \\
\hline $24-33$ & 60 & 52 & 34 & 29.5 & 94 \\
\hline $34-43$ & 37 & 32 & 30 & 26.5 & 67 \\
\hline $44-53$ & 17 & 14 & 18 & 15 & 35 \\
\hline $54-63$ & 1 & 1.1 & 15 & 13 & 16 \\
\hline $64-73$ & & 0.9 & 13 & 12 & 13 \\
\hline $74-83$ & & & 5 & 4 & 5 \\
\hline Grand Total & 115 & 100 & 115 & 100 & 230 \\
\hline
\end{tabular}

A total of 230 medical and dental professionals completed the questionnaire. The age range of the population was 24-83 years.).(Table-1) Similarly out of 98 females $(n=38$ were medical practitioners and $n=60$ were dental practitioners.

Table 2. Distribution of Respondents according to Gender

\begin{tabular}{|c|c|c|c|c|c|}
\hline & \multicolumn{5}{|c|}{ Group } \\
\hline & & & & Grand \\
Gender & Dental & $\%$ & Medical & $\%$ & Total \\
\hline Male & 55 & 48 & 77 & 67 & 132 \\
\hline Female & 60 & 52 & 38 & 33 & 98 \\
\hline Grand Total & 115 & 100 & 115 & 100 & 230 \\
\hline
\end{tabular}

Among the participants, 98 were females and 132 were males of which 132 males $(n=77$ were medical practitioners and $n=55$ were dental practitioners

Table 3. Distribution of Respondents according to Qualification

\begin{tabular}{|c|c|c|c|c|}
\hline Qualification & Dental professionals & \% & Medical professionals & \% \\
\hline BDS & $\mathbf{5 2}$ & $\mathbf{4 5}$ & & \\
\hline MDS & $\mathbf{6 3}$ & $\mathbf{5 5}$ & $\mathbf{3 3}$ & $\mathbf{2 8}$ \\
\hline MBBS & & & $\mathbf{8 2}$ & $\mathbf{7 2}$ \\
\hline Masters & $\mathbf{1 1 5}$ & $\mathbf{1 0 0}$ & $\mathbf{1 1 5}$ & $\mathbf{1 0 0}$ \\
\hline Grand Total & & & & \\
\hline
\end{tabular}


Knowledge, attitude \& practices regarding Ethics \& Law amongst medical and dental professionals in

Amongst the dental practitioners ( $n=52$ were B.D.S. and $n=63$ were M.D.S.). Amongst the medical practitioners $(\mathrm{n}=33$ of them were M.B.B.S. and $\mathrm{n}=82$ had masters degree.)

Table 4. Distribution of Respondents according to Duration of Profession

\begin{tabular}{|c|c|c|c|c|c|}
\hline Duration of professional life & Dental & $\%$ & Medical & $\%$ & Grand Total \\
\hline $0-10$ & 76 & 66.7 & 52 & 45.2 & 128 \\
\hline $10-20$ & 32 & 27.3 & 27 & 23.4 & 59 \\
\hline $20-30$ & 7 & 6 & 9 & 7.8 & 16 \\
\hline $30-40$ & & & 23 & 20 & 23 \\
\hline $40-50$ & & & 3 & 2.6 & 3 \\
\hline $50-60$ & & & 1 & .9 & 1 \\
\hline Grand Total & 115 & 100 & 115 & 100 & 230 \\
\hline \multicolumn{6}{|l|}{ Mean } \\
\hline \multicolumn{6}{|l|}{$\mathrm{SD}$} \\
\hline P-Value & & & & & \\
\hline
\end{tabular}

The duration of professional life of the medical participants ranged from 0-60 years with mean of $\mathbf{1 5 . 4}$ years while the duration of professional life of the dental participants ranged from 1-30 years with mean of 7.3 years.

Table 5. Distribution of Respondents according to Place of practice

\begin{tabular}{|c|c|c|c|c|c|}
\hline Place of Practice & Dental & $\%$ & Medical & $\%$ & Grand Total \\
\hline Clinical Practice & 36 & 31 & 14 & 12 & 50 \\
\hline hospital practice & 16 & 13 & 49 & 42 & 65 \\
\hline Both & 63 & 56 & 52 & 46 & 115 \\
\hline Grand Total & 115 & 100 & 115 & 100 & 230 \\
\hline
\end{tabular}

Amongst the dental and medical practitioners 36 and 14 had clinical practice, 16 and 49 had hospital practice while 63 and 52 doctors amongst them had both clinical and hospital practice.

Table 6. Knowledge Vs Qualification

\begin{tabular}{|c|c|c|c|c|}
\hline & \multicolumn{4}{|c|}{ Score Knowledge } \\
\hline Based on degree & $\mathrm{N}$ & Mean & SD & 1.19 \\
\hline BDS & 52 & 3.76 & 0.89 & $0.000^{*}$ \\
\hline Masters & 145 & 4.36 & 0.85 & 1.01 \\
\hline MBBS & 33 & 3.66 & 4.13 & \\
\hline
\end{tabular}

Doctors having masters degree in both the group showed to have more knowledge than the graduates(Mean of Masters 4.32 vs 3.67 of MBBS) while (Mean of MDS 4.43 vs 3.77 of B.D.S). (Table -6).

Graph-1.Knowledge Vs Institutional attachment

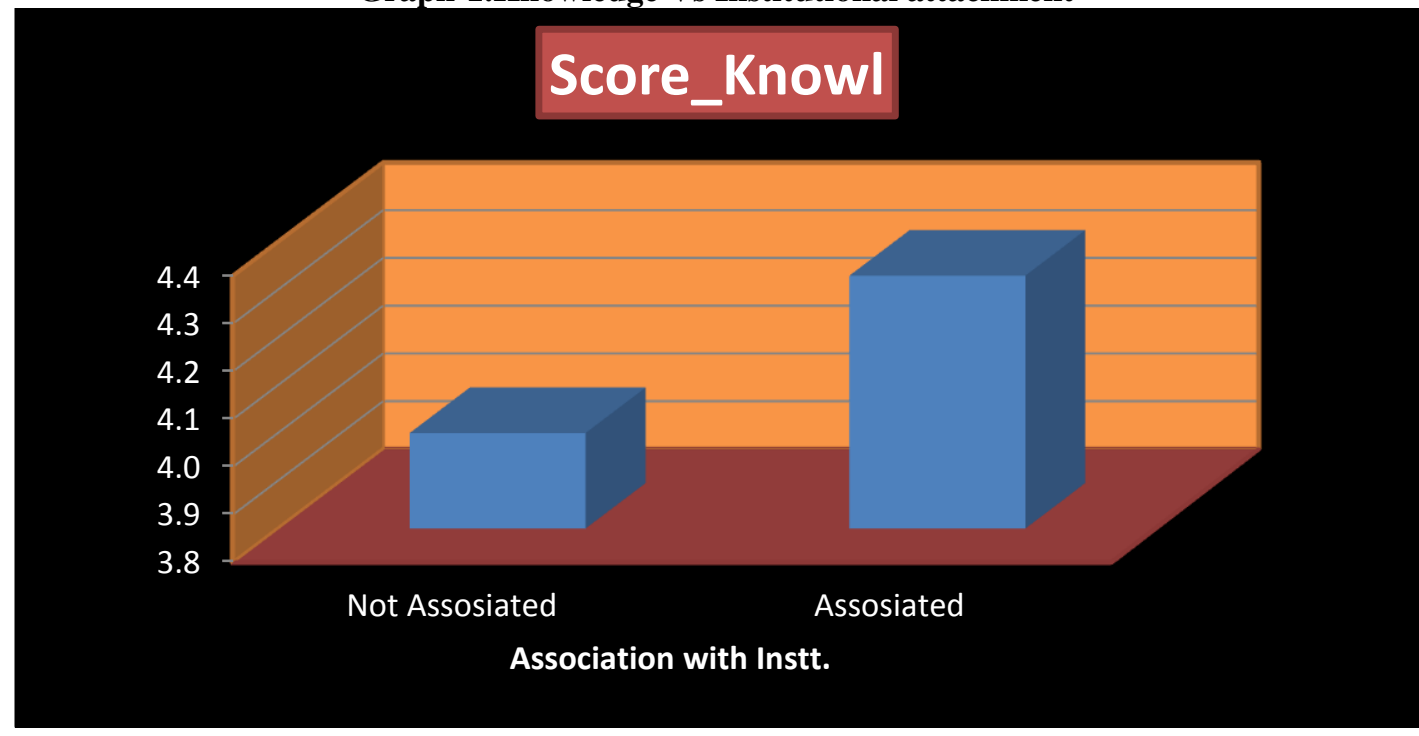


Knowledge, attitude \& practices regarding Ethics \& Law amongst medical and dental professionals in

On comparing the knowledge of the participants with institutional attachments results showed that there was statistical significance between those who were attached to a institution and those who had no attachment(mean 4.3 Vs 4.0).

Table 7. Knowledge Vs. Profession

\begin{tabular}{|c|c|c|c|c|}
\hline & \multicolumn{3}{|c|}{ Score Knowledge } \\
\hline Group & $\mathrm{N}$ & Mean & SD & P-Value \\
\hline Medical & 115 & 4.13 & 0.97 & \multirow{2}{*}{1.00} \\
Dental & 115 & 4.13 & 1.04 & \\
\hline Grand Total & 230 & 4.13 & 1.0 & \\
\hline
\end{tabular}

When the knowledge scores were compared among the two groups(i.e Dental Vs Medical practitioners) it was observed that dental professionals were found to have more knowledge compared to medical practitioners(mean 1.4 Vs 0.97 )

Table 8. Knowledge Vs. Age

\begin{tabular}{|c|c|c|c|c|}
\hline & \multicolumn{4}{|c|}{ Score Knowledge } \\
\hline Age Group & $\mathrm{N}$ & Mean & SD & P-Value \\
\hline $24-33$ & 94 & 4.01 & 1.14 & 0.84 \\
\hline $34-43$ & 67 & 4.24 & 1.01 \\
\hline $44-53$ & 35 & 4.17 & 0.81 \\
\hline $54-63$ & 16 & 4.38 & 1.19 \\
\hline $64-73$ & 13 & 4.08 & 0.71 \\
\hline $74-83$ & 5 & 4.00 & 1.01 \\
\hline
\end{tabular}

It was observed that the knowledge of the participants varied with the age but the difference was not statistically significant. Maximum knowledge was seen in that age group of 34-43 years(Mean =4.24). (Table 8).

Table 9. Knowledge Vs. Years of Professional life

\begin{tabular}{|c|c|c|c|c|}
\hline \multirow[b]{2}{*}{ Duration of Professional life } & \multicolumn{4}{|c|}{ Score Knowledge } \\
\hline & $\mathrm{N}$ & Mean & SD & P-Value \\
\hline $0-10$ & 128 & 4.02 & 1.07 & \multirow{7}{*}{0.107} \\
\hline $10-20$ & 59 & 4.38 & 0.87 & \\
\hline $20-30$ & 16 & 4.12 & 0.88 & \\
\hline $30-40$ & 23 & 3.95 & 1.02 & \\
\hline $40-50$ & 3 & 4.66 & 0.57 & \\
\hline $50-60$ & 1 & 5 & 0.00 & \\
\hline Grand Total & 230 & 4.13 & 1.01 & \\
\hline
\end{tabular}

It was obsereved that the knowledge of the participants varied with their years of professional life but the results showed no statistical difference. Knowledge was observed to be maximum in the group having work experience of 0-10 yrs. (Table -9).

Table 12. Knowledge Vs. Place of Practice

\begin{tabular}{|c|c|c|c|c|}
\hline & \multicolumn{4}{|c|}{ Score Knowledge } \\
\hline Place of Practice & N & Mean & SD Value \\
\hline Clinical Practice & 50 & 3.90 & 1.10 & \multirow{2}{*}{0.17} \\
\hline hospital practice & 65 & 4.15 & 1.06 & \\
\hline Both & 115 & 4.21 & 0.92 & \\
\hline Grand Total & 230 & 4.13 & 1.01 & \\
\hline
\end{tabular}

Knowledge of the doctors was compared with their place of practice i.e. they were practicing in a hospital or a clinic or had both hospital and clinical practice. It was seen that there was no significant difference 
Knowledge, attitude \& practices regarding Ethics \& Law amongst medical and dental professionals in

regarding their place of practice.(Mean of Clinical practice $3.90 \mathrm{Vs} 4.15$ of hospital practice Vs 4.21 of both hospital and clinical practice.)(Table-12)

Table 13. Attitude Vs Age

\begin{tabular}{|c|c|c|c|c|}
\hline & \multicolumn{3}{|c|}{ Score Attitude } \\
\hline Age group & $\mathrm{N}$ & Mean & SD & 0.44 \\
\hline $24-33$ & 94 & 0.27 & 0.49 \\
\hline $34-43$ & 67 & 0.41 & 0.50 \\
\hline $44-53$ & 35 & 0.57 & 0.51 \\
\hline $54-63$ & 16 & 0.5 & 0.43 \\
\hline $64-73$ & 13 & 0.23 & 1 \\
\hline $74-83$ & 5 & 1 & $0.001 *$ \\
\hline
\end{tabular}

It was observed that the attitude of the participants varied with age and the difference amongst the groups was statistically significant. Best attitude was seen amongst the age group from 44-53 yrs.(Mean=0.57) (Table-13).

Table 14.Attitude Vs Years of Professional life

\begin{tabular}{|c|c|c|c|c|}
\hline & \multicolumn{3}{|c|}{ Score Attitude } \\
\hline Duration of Professional life & $\mathrm{N}$ & Mean & SD & 0.44 \\
\hline $0-10$ & 128 & 0.27 & 0.49 \\
\hline $10-20$ & 59 & 0.61 & 0.51 \\
\hline $20-30$ & 16 & 0.43 & 0.48 \\
\hline $30-40$ & 23 & 0.34 & 0 \\
\hline $40-50$ & 3 & 1 & 0.00 \\
\hline $50-60$ & 1 & 1 & 0.39 & 0.48 \\
\hline
\end{tabular}

Attitude of the participants also varied with their work experience and it had statistical significance and best attitude was seen in group which has duration of profession between 10-20 years.(Mean=0.61)(Table14)

Table 15. Attitude Vs Place of Practice

\begin{tabular}{|c|c|c|c|c|}
\hline & \multicolumn{4}{|c|}{ Score practice } \\
\hline
\end{tabular}

When attitude of doctors was compared with their place of practice (clinical, Hospital or both) it was seen that doctors who were associated with both clinical and hospital practice had best attitude compared to those who had clinical practice and hospital practice and the difference was statistically significant.(Mean=0.47 vs 0.30 vs 0.32 )(Table-15).

Table 16. Attitude Vs Qualification

\begin{tabular}{|c|c|c|c|c|}
\hline & \multicolumn{4}{|c|}{ Score Attitude } \\
\hline Qualification & N & Mean & SD & Palue \\
\hline BDS & 52 & 0.25 & 0.43 & \multirow{2}{*}{$0.003^{*}$} \\
\hline Masters & 145 & 0.47 & 0.50 & 0.43 \\
\hline MBBS & 33 & 0.24 & 0.48 & \\
\hline Grand Total & 230 & 0.39 & & \\
\hline
\end{tabular}

Attitude of masters in both the group had positive attitude and showed statistical significance. (Table-16). 
Knowledge, attitude \& practices regarding Ethics \& Law amongst medical and dental professionals in

Table 17. Attitude Vs Profession

\begin{tabular}{|c|c|c|c|c|}
\hline & \multicolumn{3}{|c|}{ Score Attitude } \\
\cline { 1 - 3 } Group & N & Mean & SD & \multirow{2}{*}{0.537} \\
\hline Medical & 115 & 0.40 & 0.49 & \\
\hline Dental & 115 & 0.37 & 0.47 & \\
\hline Grand Total & 230 & 0.39 & 0.48 & \\
\hline
\end{tabular}

It was observed that medical practitioners had slightly better attitude than dental practitioners. The difference in the attitude of dental and medical practitioners showed no statistical significance.(Mean of Medical 0.40 Vs 0.37 of Dental).(Table-17)

Table 18. Attitude Vs Years of Institutional attachment

\begin{tabular}{|c|c|c|c|c|}
\hline & \multicolumn{3}{|c|}{ Score Attitude } \\
\hline Duration of Institutional.Attachment & $\mathrm{N}$ & Mean & SD & P-Value \\
\hline $0-10$ & 212 & 0.37 & 0.48 & 0.49 \\
\hline $10-20$ & 12 & 0.66 & 0.58 & 0.144 \\
\hline $20-30$ & 3 & 0.70 & 0.57 \\
\hline $30-40$ & 3 & 0.33 & 0.48 \\
\hline
\end{tabular}

There was highest in the institutional attachment in 0 to 10 years of age with the mean of 0.37 and lowest in 20 to 30 years and 30 to 40 years with the mean of 0.33 and 0.40 .

Table 19. Practice Vs Profession(Medical and Dental)

\begin{tabular}{|c|c|c|c|c|}
\hline & \multicolumn{3}{|c|}{ Score practice } \\
\hline Group & $\mathrm{N}$ & Mean & SD & P-Value \\
\hline Medical & 115 & 6.13 & 1.32 & 0.86 \\
\hline Dental & 115 & 6.16 & 1.36 & 1.34 \\
\hline Grand Total & 230 & 6.14 & 2 \\
\hline
\end{tabular}

When practice scores of the participants were compared among both the groups on the basis of their profession, it was observed that dental practitioners showed slightly better practice behavior than medical practitioners but the difference in practice behavior among both the groups was not statistically significant.(Mean of Dental 6.16 Vs 6.13 of Medical)(Table 19)

Table 20. Practice Vs Qualification

\begin{tabular}{|c|c|c|c|c|}
\hline & \multicolumn{3}{|c|}{ Score practice } \\
\hline Qualification & $\mathrm{N}$ & Mean & SD & 1.42 \\
\hline BDS & 52 & 6.1 & 1.32 \\
\hline Masters & 145 & 6.1 & 1.30 \\
\hline MBBS & 33 & 6.0 & 1.34 \\
\hline
\end{tabular}

When practice scores of the participants were compared with their qualifications among both the groups it was observed that there was no statistical significant difference among undergraduates and Post graduates in both the groups regarding their practice behavior.(Table-20)

Table 21. Practice Vs. Place of Practice

\begin{tabular}{|c|c|c|c|c|}
\hline & \multicolumn{4}{|c|}{ Score Attitude } \\
\hline Place of Practice & $\mathrm{N}$ & Mean & SD & P-Value \\
\hline Clinical Practice & 50 & 0.3 & 0.46291 & 0.471291 \\
\hline hospital practice & 65 & 0.3230769 & 0.501257 \\
\hline Both & 115 & 0.4695652 & 0.489107 & \\
\hline Grand Total & 230 & 0.3913043 & 0.47 & \\
\hline
\end{tabular}


It was observed that Practitioners who were associated with both clinical and hospital practice had better practice score compared to hospital practice and private practice and showed statistical significance.(Mean 0.47 vs 0.32 vs 0.30 )(Table-21).

Table 22. Practice Vs Age

\begin{tabular}{|c|c|c|c|c|}
\hline & \multicolumn{3}{|c|}{ Score Practice } \\
\hline AGE Group & N & Mean & SD & \multirow{2}{*}{ Salue } \\
\hline $24-33$ & 94 & 6.1 & 1.45 & \multirow{2}{*}{0.38} \\
\hline $34-43$ & 67 & 6.3 & 1.12 \\
\hline $44-53$ & 35 & 5.7 & 1.49 \\
\hline $54-63$ & 16 & 5.8 & 1.14 & \\
\hline $64-73$ & 13 & 6.3 & 1.26 & \\
\hline $74-83$ & 5 & 6.2 & 1.48 \\
\hline Grand Total & 230 & 6.1 & 1.34 & \\
\hline
\end{tabular}

It was observed that the practice scores of the participants varied with age and the difference amongst the groups was not statistically significant. Best practice behavior was seen amongst the age group from 34-43 yrs. $($ Mean=6.3) Table-21.

Table 23. PracticeVs. Years of Professional life

\begin{tabular}{|c|c|c|c|c|}
\hline & \multicolumn{3}{|c|}{ Score Attitude } \\
\hline Duration of Proffessional life & N & Mean & SD & P-Value \\
\hline $0-10$ & 128 & 0.27 & 0.44 & \multirow{2}{*}{$0.000 *$} \\
\hline $10-20$ & 59 & 0.61 & 0.49 & \\
\hline $20-30$ & 16 & 0.43 & 0.51 & \\
\hline $30-40$ & 23 & 0.34 & 0.48 & 1 \\
\hline $40-50$ & 3 & 1 & 1 & \\
\hline $50-60$ & 1 & 1 & 0.49 & \\
\hline Grand Total & 230 & 0.39 & 0.29 \\
\hline
\end{tabular}

Practice scores of the participants also varied with their work experience and the difference in the scores was highly significant. Best practice behavior was found in the age group from 10-20 yrs.(Mean $=0.61)($ P value- $0.000 *)$. (Table -23$)$

\section{Discussion}

There has been growing public concern regarding the ethical conduct of health care professionals. The role of ethics has become a moral, legal and basic need for almost all stages of clinical practice. The present study however identified some of the major and important gaps of knowledge and attitude in recognizing the importance of using ethical principles in their profession.

In present study the masters in both the groups had more knowledge and positive attitude when compared to undergraduates and this gap could easily be ascribed to the deficiencies in curriculum and also the fact that masters go for more workshops, CME conferences which enhances their knowledge and attitude. The results of the present study were parallel with the results of study conducted by Walrond et.al in 2006 in which majority of the participants had answered correctly to the questions based on ethical knowledge. ${ }^{6}$

In the present study it was observed that participants who were associated with institution had more knowledge in comparison with those had no attachment this may be due to the fact that they are in touch with academics, curriculum and various recent advances.

The present study also showed a close relationship between attitude and increase in age and work experience which show similar findings conducted by Chopra M. et. al 2013 and Brogen SA in 2009.This can be due to the fact, Since healthcare ethics is not taught in the undergraduate level, it is more likely that senior doctors will have better knowledge and attitude either by experience or age. ${ }^{7,8}$

In the present study when professionals were asked questions based on their practice behavior then it was observed that majority of the participants from both medical and dental professionals were aware of common ethical issues and this may be due to the fact that questions based on practice were simple and easy to answer as they were based on basic moral principles and results show close affirmation with the study conducted by Hariharan $\mathbf{S}$ in 2006.Practitioners who were associated with both clinical and hospital practice 
had better practice score compared to private practitioners this may be due to the fact that they work under scientific ethics committee which allow them to work under the ethical principles. ${ }^{9}$

\section{Conclusion}

In summary, the medical and dental professionals of Jaipur city generally understand the importance of Ethics and law, as majority of participants answered correctly on questions based on knowledge attitude and practice. There were substantial minority of participants who were uncertain or incorrect on the questions pertaining to violent, AIDS patients and religious conflict situations.

The knowledge and attitude of the masters were more compared to undergraduates thus study emphasize the need to provide the knowledge of healthcare ethics in curriculum and use of interactive techniques such as Seminars, Workshops, CME conferences which would assist in bridging this gap to certain extent at undergraduate level.

\section{References}

[1]. Reading material for on-line post graduate diploma course in bio ethics under ICMR and IGNOU joint initiative, 2011.

[2]. Agich GJ. What kind of doing is clinical ethics? Theor Med Bioeth.2005;26(1):7-24.

[3]. Aarons DE. Issues in bioethics to healthcare professionals. West Indian Med J.2002. Jun ;51(2);59-63.

[4]. HowittM.Medicalethics.Barbados Association of Medical Practitioners Bulletin.2002;152-5.

[5]. Roff S, PreeceP.Helping medical students to find their moral compasses: Ethics teaching for second and third year undergraduates.J Med Ethics.2004 Oct;30(5):487-9.

[6]. Walrond ER, Jonnalagadda R, Hariharan S, Moseley HSL. Knowledge, attitudes and practice of medical students at the Cave Hill campus in relation to ethics and Law in health care. West Indian Med J 2006;55(1):42.

[7]. Chopra M, Bhardwaj A, Mithra P et al. Current status of knowledge, attitudes and practices towards health care ethics among doctors and nurses from Northern India-A multicenter study. JKIMSU, Vol 2, No 2, July-December 2013.

[8]. Brogan SA, Rajkumari B, Laishram J, Joy A. Knowledge and attitude of doctors on medical ethics in a teaching hospital, Manipur. Indian Jouranl of Medical ethics 2009;6(4): 194-7.

[9]. Hariharan S, Jonnalgadda R, Walrond E and Moseley H. Knowledge, attitude and practices of healthcare ethics and law among doctors and nurses in Barbados. BMC Medical Ethics 2006, 7:7-16. 